\title{
PENERAPAN MODEL PEER LED TEAM LEARNING UNTUK MENINGKATKAN HASIL BELAJAR DAN SIKAP SISWA TERHADAP KIMIA
}

\section{IMPLEMENTATION OF PEER LED TEAM LEARNING MODEL TO IMPROVE STUDENT LEARNING OUTCOME AND ATTITUDE TOWARD CHEMISTRY}

\author{
Yunita Arian Sani Anwar ${ }^{1 *}$, Hariantini \\ ${ }^{1}$ Program Studi Pendidikan Kimia, Fakultas Keguruan dan Ilmu Pendidikan, Universitas Mataram, Indonesia \\ ${ }^{2}$ Madrasah Aliyah Negeri 2 Mataram, Nusa Tenggara Barat, Indonesia \\ *Email: yunita@unram.ac.id
}

Diterima: 18 Januari 2019. Disetujui: 02 Maret 2019. Dipublikasikan: 31 Maret 2019

\begin{abstract}
Abstrak: Reaksi redoks merupakan materi yang masih dianggap sulit oleh siswa sekolah menengah atas. Penggunaan model yang dapat meningkatkan motivasi belajar diharapkan mampu mengatasi kesulitan belajar siswa. Peer Led Team Learning (PLTL) adalah salah satu model pembelajaran yang memiliki keunggulan untuk dapat mengatasi kesulitan siswa dalam belajar reaksi redoks. Penelitian ini bertujuan untuk mengetahui penerapan PLTL terhadap hasil belajar dan sikap siswa terhadap kimia. Desain penelitian yang digunakan adalah penelitian tindakan kelas (PTK) dengan model Kurt Lewin sebanyak 2 siklus. Pelaksanaan pada kelas XII MAN 2 Mataram dengan jumlah siswa sebanyak 44. Hasil penelitian pada siklus I menunjukkan bahwa rata-rata skor hasil belajar siswa sebesar 64,64 dan sikap terhadap kimia menunjukkan rata-rata sebesar 4,19. Perbaikan yang dilakukan pada siklus II sebagai hasil refleksi siklus I adalah menggunakan demonstrasi sederhana dan mengatur kembali anggota kelompok siswa. Siklus II menunjukkan peningkatan skor hasil belajar dan sikap terhadap kimia masing-masing sebesar 72,27 dan 4,41. Dengan demikian, penerapan model PLTL mampu meningkatkan hasil belajar dan sikap terhadap kimia siswa MAN 2 Mataram pada pokok bahasan reaksi redoks.
\end{abstract}

Kata Kunci : Peer Led Team Learning, Hasil Belajar, Sikap Terhadap Kimia, Reaksi Redoks

\begin{abstract}
Secondary school of student have difficulty learning about redox reaction. To solve this problem, requires learning model that can increase learning motivation. Peer Led Team Learning (PLTL) is a model that have benefit to resolve difficulty learning of student. The purpose of this study was to investigate implementation a PLTL on secondary school students' learning outcome and attitude toward chemistry. Research design using classroom action research of Kurt Lewin model with 2 cycles. The result of first cycle showed that learning outcome score was 64.64 and attitude toward chemistry score was 4.19 . Reflection result were using simple demonstration and rearrange of teamwork. Second cycle showed that learning outcome and attitude toward chemistry score was 72.27 and 4.41 respectively. Therefore the implementation of PLTL can improve learning outcome and attitude toward chemistry of MAN 2 Mataram student of redox reaction.
\end{abstract}

Keywords : Peer Led Team Learning, Learning Outcomes, Attitude Toward Chemistry, Redox Reaction

\section{PENDAHULUAN}

Belajar kimia seperti halnya belajar ilmu yang lain dipengaruhi oleh beberapa faktor, salah satunya adalah motivasi. Siswa dengan motivasi yang tinggi akan memiliki hasil belajar yang baik [1]. Namun, hingga kini kimia masih menjadi mata pelajaran paling sulit menurut siswa. Penelitian Broman et al. [2] pada siswa yang berada di 25 negara menunjukkan tanggapan yang negatif terhadap kimia. Kondisi yang sama juga terjadi di Indonesia yang tergambar dari hasil Trends in Mathematics and Science Study (TIMSS) menunjukkan estimasi kemampuan rata-rata siswa Indonesia pada konten kimia menempati peringkat 45 dari 48 negara [3].

Reaksi redoks merupakan pokok bahasan yang dekat dengan kehidupan siswa sehingga seyogianya dapat meningkatkan ketertarikan siswa [4]. Namun, penelitian Broman et al. [2] menunjukkan bahwa reaksi reduksi oksidasi merupakan pokok bahasan yang paling sulit dibandingkan pokok bahasan yang lain. Padahal, reaksi redoks merupakan pokok bahasan yang penting untuk dapat memahami fenomena yang ada di sekitar kita.

Perlunya meningkatkan motivasi belajar siswa dengan menggunakan model pembelajaran yang menarik bagi siswa [5-7]. Model pembelajaran yang digunakan diharapkan dapat meningkatkan motivasi siswa sehingga hasil belajar siswa dapat meningkat. Selain itu, sikap siswa terhadap kimia diharapkan dapat meningkat seperti halnya hasil belajar [8-11].

Peer Led Team Learning (PLTL) adalah salah satu model pembelajaran yang mengutamakan pembelajaran aktif [12]. Model ini termasuk model pembelajaran kooperatif yang tidak hanya berisi 
pembelajaran akademik namun memadukannya dengan keterampilan sosial. Model PLTL memiliki langkah yang unik dibandingkan model kooperatif lainnya. Seorang yang berperan sebagai leader (ketua) bertanggung jawab agar teman dalam kelompoknya mampu menyelesaikan masalah yang diberikan oleh guru. Suatu kelompok dapat berhasil dan memperoleh reward apabila siapapun anggota yang dipilih untuk menjawab soal mampu menyelesaikannya dengan baik [13].

PLTL seperti halnya pembelajaran kooperatif lainnya memiliki lima pilar pendukung yaitu positive interdependence, face to face interaction, individual accountability, social skill, dan group processing [16]. Positive interdependence didefinisikan sebagai ketergantungan positif antara anggota kelompok sehingga seseorang tidak akan berhasil kecuali semua anggota kelompok berhasil. Face to face interaction berperan dalam pembagian tugas sehingga semua anggota tim berperan penting dalam proses pembelajaran. Individual accountability melatih setiap individu bertanggung jawab terhadap tugas yang diberikan kepadanya. Social skill menunjukkan kemampuan seseorang dalam pengambilan keputusan dan membangun kepercayaan diri dan anggota kelompok. Group processing menggambarkan kemampuan anggota tim untuk berdiskusi tentang tindakan dan sikap yang harus dilakukan, dihindari dan dipertahankan agar proses pembelajaran berlangsung dengan baik. Kelima pilar ini akan bermuara pada peningkatan proses pembelajaran $[13,15]$.

Penggunaan PLTL tidak pernah digunakan oleh guru dalam proses pembelajaran kimia di MAN 2 Mataram. Penelitian ini bertujuan untuk mengetahui penerapan model PLTL terhadap hasil belajar dan sikap siswa terhadap kimia.Belajar merupakan kegiatan yang kompleks yang membuat siswa dapat menjadi generasi kreatif yang dapat menyelesaikan permasalahan yang terjadi di lingkungan sekitar. Pembelajaran IPA mengembangkan pemahaman tentang berbagai macam gejala alam, konsep, prinsip IPA yang bermanfaat dan dapat diterapkan dalam kehidupan sehari-hari. Kegiatan pembelajaran yang efektif sangat dibutuhkan siswa untuk membantu mengembangkan daya pikir siswa dengan tanpa mengesampingkan tingkat pemahaman siswa sesuai dengan usia perkembangannya. Berdasarkan KTSP 2006 tujuan dari pembelajaran IPA adalah agar siswa memiliki kemampuan untuk mengembangkan pengetahuan yang dimilikinya dan dikaitkan dengan konsep-konsep IPA yang diperoleh pada saat mengikuti proses belajar dan dapat diterapkan dalam kehidupan [1]. Proses pembelajaran IPA menekankan pada pemberian pengalaman langsung untuk mengembangkan kompetensi agar menjelajahi dan memahami alam sekitar secara ilmiah.

\section{METODE PENELITIAN \\ Implementasi Model PLTL}

Model PLTL terdiri atas 6 fase pembelajaran. Fase pertama yaitu memberikan motivasi kepada siswa melalui penyampaian fakta dan tujuan mempelajari pokok bahasan reaksi redoks. Fase kedua ada penyajian informasi kepada siswa terkait materi redoks. Fase ketiga adalah pengorganisasian siswa dalam kelompok belajar. Jumlah anggota kelompok sebanyak 4 orang dengan tingkat kemampuan yang bervariasi. Guru memberikan tugas yang harus dikerjakan dan menunjuk satu orang siswa yang berperan sebagai leader. Fase keempat adalah menyelesaikan tugas yang diberikan dan melakukan pembahasan di kelas. Guru menunjuk perwakilan masing-masing kelompok untuk mengerjakan di depan kelas. Fase kelima melakukan evaluasi secara individu. Fase keenam adalah pemberian penghargaan kepada siswa. Keenam fase diselesaikan selama tiga pertemuan dengan durasi 1 pertemua selama 80 menit.

\section{Desain Penelitian}

Penelitian yang digunakan adalah penelitian tindakan kelas (PTK) dengan model Kurt Lewin. Model ini memiliki 4 komponen yaitu perencanaan (planning), tindakan (acting), pengamatan (observing), dan refleksi (reflection). Hubungan keempat komponen ditunjukkan pada Gambar 1.

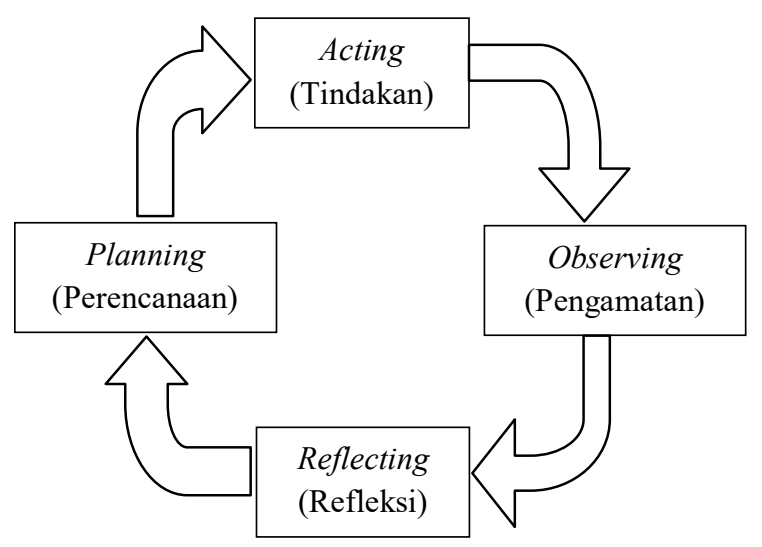

Gambar 1. Model PTK Kurt Lewin

Perencanaan meliputi penentuan waktu dan sampel penelitian, penyusunan RPP dengan teknik lesson study antara peneliti, guru pengampu, guru mitra, dan ahli, penyusunan instrumen penelitian, mengukur validitas dan reliabilitas instrumen, serta menyiapkan siswa dalam proses pembelajaran. Tahap tindakan adalah implementasi model PLTL sebanyak 6 fase. Pelaksanaan pada kelas XII MAN 2 Mataram dengan jumlah siswa sebanyak 44 siswa. Tahap observasi adalah peneliti dibantu oleh guru 
kelas sebagai observer untuk mencatat temuan penting selama penelitian. Hasil observasi pada setiap pertemuan dianalisis sebagai bahan perbaikan kegiatan pembelajaran. Tahap refleksi adalah tahap peninjauan kegiatan pembelajaran. Hasil refleksi digunakan untuk merencanakan tahap pembelajaran berikutnya. Penelitian ini dilakukan sebanyak 2 siklus, masing-masing siklus dilakukan selama 4 kali pertemuan dengan 1 pertemuan berdurasi selama 8 menit.

\section{Instrumen Penelitian}

Penelitian ini menggunakan dua jenis instrumen pengumpul data yaitu soal oksidasi reduksi dan kuesioner attitude toward chemistry. Soal oksidasi reduksi menggunakan 8 indikator pada kedua siklus seperti yang ditunjukkan pada Tabel 1.

Tabel 1. Indikator Pencapaian pada Kedua Siklus

\begin{tabular}{|c|c|}
\hline Kode & $\begin{array}{l}\text { Indikator } \\
\end{array}$ \\
\hline I1 & $\begin{array}{l}\text { Menjelaskan hakikat reaksi redoks } \\
\text { berkaitan dengan penurunan dan } \\
\text { kenaikan bilangan oksidasi. }\end{array}$ \\
\hline $\mathrm{I} 2$ & $\begin{array}{l}\text { Memahami cara menentukan bilangan } \\
\text { oksidasi (biloks) suatu atom atau } \\
\text { unsur dalam molekul, ion, atau } \\
\text { senyawa. }\end{array}$ \\
\hline $\mathrm{I} 3$ & $\begin{array}{l}\text { Menyetarakan reaksi redoks dengan } \\
\text { metode setengah reaksi (ion elektron) }\end{array}$ \\
\hline $\mathrm{I} 4$ & $\begin{array}{l}\text { Menyetarakan reaksi redoks dengan } \\
\text { metode perubahan bilangan oksidasi } \\
(\mathrm{PBO}) \text {. }\end{array}$ \\
\hline I5 & $\begin{array}{l}\text { Menjelaskan cara reaksi redoks dalam } \\
\text { sel volta dalam menghasilkan energi } \\
\text { listrik }\end{array}$ \\
\hline I6 & $\begin{array}{l}\text { Menuliskan lambang/notasi sel dan } \\
\text { reaksi-reaksi yang terjadi pada sel } \\
\text { volta }\end{array}$ \\
\hline I7 & $\begin{array}{l}\text { Menghitung potensial sel berdasarkan } \\
\text { data potensial standar }\end{array}$ \\
\hline I8 & $\begin{array}{l}\text { Menjelaskan deret keaktifan logam } \\
\text { (deret volta) }\end{array}$ \\
\hline
\end{tabular}

Kuesioner attitude toward chemistry berisi pernyataan postif dan negatif siswa terkait mata pelajaran kimia. Terdapat tiga kategori yang digunakan yaitu kesukaan terhadap kimia, kepercayaan terhadap kimia di sekolah, dan kecenderungan sikap untuk belajar kimia. Masingmasing kategori dikembangkan menjadi tiga pernyataan positif dan negatif [11]. Setiap pernyataan memiliki lima skala jawaban yaitu sangat setuju, setuju, ragu-ragu, tidak setuju, sangat tidak setuju. Kedua instrumen diukur validitas dan reliabilitasnya menggunakan kesepakatan ahli menggunakan 3 ahli pendidikan kimia. Validitas instrumen ditunjukkan oleh Aiken index, sedangkan reliabilitas instrumen menggunakan ICC karena ahli lebih dari satu [17,
18]. Hasil Aiken index dan skor ICC menunjukkan bahwa instrumen valid dan reliabel.

\section{Teknik Analisis Data}

Hasil belajar siswa dihitung rata-rata pencapaian pada masing-masing siklus. Jika skor mengalami peningkatan menunjukkan model PLTL dapat meningkatkan hasil belajar siswa pada pokok bahasan reaksi redoks. Kuesioner attitude toward chemistry dianalisis masing-masing pernyataan untuk mengetahui respon siswa terhadap pelajaran kimia.

\section{HASIL DAN PEMBAHASAN \\ Siklus I}

Indikator yang digunakan pada siklus I adalah indikator I1-I4 pada penyetaraan reaksi oksidasi reduksi. Mahasiswa dibagi menjadi beberapa kelompok, masing-masing kelompok terdiri atas 4 orang sisiwa. Setiap kelompok dipilih leader yang bertugas membantu temannya memahami materi yang diberikan. Pemilihan leade dibantu oleh guru kelas yang telah mengetahui kemampuan siswa dengan baik. Masing-masing kelompok diberikan tugas setelah mendapatkan penjelasan dari guru. Evaluasi diberikan secara individu dan kelompok yang mendapatkan reward apabila rata-rata hasil evaluasi masing-masing anggota kelompoknya memperoleh nilai tertinggi.

Hasil siklus I menunjukkan beberapa kelompok terlihat antusias berdiskusi bersama untuk dapat memahami materi. Evaluasi menunjukkan sebanyak tiga kelompok mendapatkan nilai rata-rata tertinggi untuk memperoleh reward. Skor hasil belajar siswa diperoleh rata-rata sebesar 64,64. Hasil analisis jawaban masing-masing indikator menunjukkan bahwa penyetaraan reaksi redoks dengan metode setengah reaksi menunjukkan hasil terendah yaitu sebesar 50, sedangkan hasil tertinggi ditunjukkan pada indikator reaksi redoks yang berkaitan dengan penurunan dan kenaikan bilangan oksidasi sebesar 76,82. Rata-rata hasil belajar siswa untuk masingmasing indikator ditunjukkan pada Gambar 2.

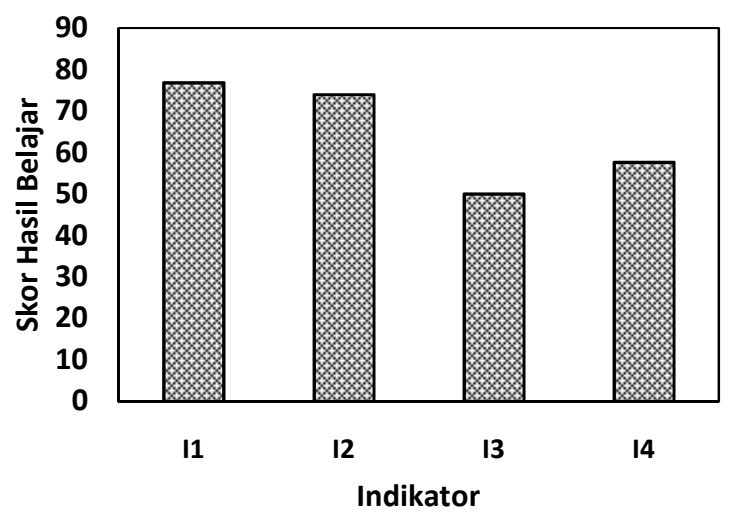

Gambar 2. Skor Hasil Belajar Siklus I 
Analisis attitude toward chemistry menunjukkan bahwa ketiga kategori memberikan tanggapan yang positif oleh siswa. Kecenderungan sikap untuk belajar kimia, kepercayaan terhadap kimia di sekolah, dan kesukaan terhadap kimia memberikan tanggapan yang positif dengan rata-rata skor sebesar 4,19 . Skor masing-masing kategori sikap terhadap kimia ditunjukkan pada Gambar 3.

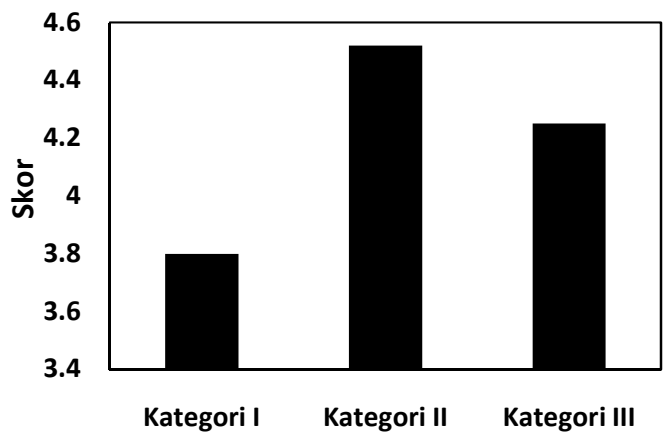

Gambar 3. Skor Sikap Terhadap Kimia pada Siklus I

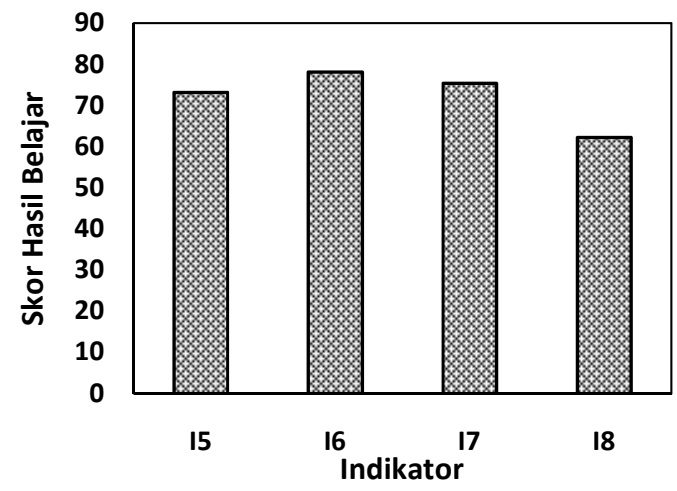

Gambar 4. Skor Hasil Belajar Siklus II

Hasil refleksi memberikan beberapa perbaikan pada pembelajaran siklus II. Perbaikan tersebut meliputi perlu lebih banyak menampilkan hal menarik untuk dapat memotivasi siswa di awal pembelajaran. Hasil diskusi dengan guru kelas disepakati Leader kelompok yang mendapatkan skor rata-rata tertinggi ditukar ke kelompok yang memiliki rata-rata rendah dan penggunaan demonstrasi sederhana.

\section{Siklus II}

Sub pokok bahasan yang digunakan pada siklus II adalah sel volta dengan 4 indikator. Sesuai dengan hasil refleksi, beberapa kelompok ditukar anggotanya agar leader dapat membantu siswa lain dalam memahami materi. Tahapan awal pembelajaran menggunakan video dan demonstrasi sederhana.

Hasil siklus 2 menunjukkan rata-rata hasil belajar siswa lebih tinggi dibandingkan siklus I dengan rata-rata 72,27 . Siswa telah memahami reaksi oksidasi reduksi serta meramalkan reaksi dapat berlangsung secara spontan atau tidak. Rata-rata hasil belajar siswa untuk masing-masing indikator ditunjukkan pada Gambar 4.

Sikap terhadap kimia mengalami peningkatan pada siklus II dengan rata-rata skor sebesar 4,41. masing-masing kategori mengalami peningkatan seperti yang ditunjukkan pada Gambar 5.

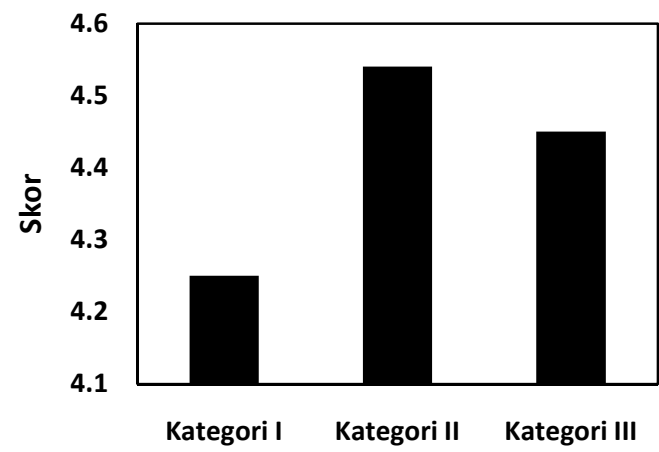

Gambar 5. Skor Sikap Terhadap Kimia pada Siklus II

Penerapan model PLTL memberikan hasil yang positif terhadap peningkatan hasil belajar dan sikap siswa terhadap kimia. Hal ini disebabkan oleh adanya kohesi sosial yang dapat meningkatkan motivasi siswa. Penggunaan PLTL memberikan dorongan pada semua anggota kelompok untuk berupaya dan saling mendukung agar dapat memperoleh hasil sebaik mungkin [14]. Hal ini membantu mengurangi kesenjangan antara siswa yang cepat memahami dengan siswa yang lambat memahami [20].

Selain meningkatkan motivasi siswa, penerapan model PLTL dapat meningkatkan kemampuan kognitif siswa dengan bantuan leader. Penelitian yang dilakukan oleh Pamela White et al. [21] menemukan bahwa kerjasama yang baik antar leader dan anggota tim mampu meningkatkan pemahaman siswa dan mengaplikasikannya di kelas. Selain kemampuan kognitif, keterangan laboratorium juga dapat terasah melalui model PLTL [22].

Berdasarkan teori perkembangan, penerapan model PLTL dapat meningkatkan perkembangan siswa. Penunjukan leader memberikan tanggung jawab kepada siswa sehingga hal ini dapat membantu mereka untuk melatih rasa tanggung jawab. Selain itu, rasa percaya diri dan kemampuan intelektual leader dapat terasah sehingga merasa tertantang untuk dapat membantu temannya [23]. Namun, kemampuan dan sikap leader bukanlah penentu keberhasilan anggota tim. Koeslag-Kreuner et al. [24] menemukan bahwa tingkah laku anggota kelompok belajar yang menjadi penentu keberhasilan siswa. 


\section{KESIMPULAN}

Penerapan model Peer Led Team Learning mampu meningkatkan hasil belajar reaksi reduksi oksidasi siswa MAN 2 Mataram selama dua siklus pembelajaran. Sikap siswa terhadap kimia mengalami peningkatan dari siklus I ke siklus II pada penerapan model PLTL.

\section{DAFTAR PUSTAKA}

[1] Everaert, P., Opdecam, E., \& Maussen, S. (2017). The relationship between motivation, learning approaches, academic performance and time spent. Accounting Education 26(1), 78107.

[2] Broman, K., Ekborg, M., \& Johnels, J. (2011). Chemistry in crisis? Perspectives on teaching and learning chemistry in Swedish upper secondary schools. Nordina, 7(1), 43-53.

[3] Kementerian Pendidikan Nasional. (2010). Analisis Kemampuan Sains Domain Konten dan Kognitif Siswa Indonesia Kelas VIII SMP/MTs Berdasarkan Data TIMSS 2007. Jakarta: Pusat Penilaian Pendidikan Badan Penelitian dan Pengembangan Kementerian Pendidikan Nasional.

[4] Thomas, G.P., \& Anderson, D. (2014). Changing the metacognitive orientation of a classroom environment to enhance students' metacognition regarding chemistry learning. Learning Environment Resouces, 17, 139-155.

[5] Adnan, M.A.M., Nordin, M.S., Ibrahim, M.B. (2013). Relationship between strategies and motivation by using structural equation modeling approach. The Malaysian Online Journal of Educational Science, 1(3), 33-40.

[6] Rahmayanti, N., Muntari, M., \& Siahaan, J. (2014). Pengaruh Penerapan Model Pembelajaran Diskusi Kelas dengan Teknik Buzz Group Terhadap Prestasi Belajar Siswa Kimia Materi Pokok Hidrokarbon. Jurnal Pijar MIPA, 9(1).

[7] Ningsyih, S., Junaidi, E., \& Al Idrus, S. W. (2016). Pengaruh Pembelajaran Praktikum Berbasis Inkuiri Terbimbing Terhadap Kemampuan Berpikir Kritis Dan Hasil Belajar Kimia Siswa. Jurnal Pijar Mipa, 11(1).

[8] Rubini, B., \& Liliasari. (2013). Basic Natural Sciences Contribution for Scientific Attitude Development and Values of Life. International Journal of Science and Research 2 (5), 465468.

[9] Azizah, N. (2016). Pengembangan Lks Dan Penerapannya Dalam Pembelajaran Kooperatif Tipe STAD Untuk Meningkatkan Aktivitas dan Hasil Belajar Kimia Siswa. Jurnal Pijar Mipa, 11(1).

[10] Qomaliyah, E. N., Sukib, S., \& Loka, I. N. (2017). Pengaruh model pembelajaran inkuiri terbimbing berbasis literasi sains terhadap hasil belajar materi pokok larutan penyangga. Jurnal Pijar Mipa, 11(2).

[11] Yulianti, R., Muntari, M., \& Haris, M. (2015). Pengaruh model pembelajaran kooperatif tipe two stay two stray (tsts) dengan pendekatan brain-based learning terhadap hasil belajar kimia materi pokok struktur atom dan sistem periodik unsur pada siswa kelas $\mathrm{x}$ sman 1 kediri. Jurnal pijar MIPA, 10(1).

[12] Daud, S., Chaudhry, A.M., Ali, S.K. (2016). Lecture based peer assisted learning: quasi experimental study to compare knowledge gain of fourth year medical students in community health and nutrition course. Res Dev Med Educ, $5(2), 62-68$.

[13] Felder RM \& Brent R. 2007. Cooperative Learning. P.A. Mabrouk, ed., Active Learning: Models from the analytical sciences, ACS symposium series 970, Chapter 4, pp. 34-53. Washington DC: American Chemical Society.

[14] Dooly, M. 2008. Contructing knowledge together (21-45). Extract from telecollaborative language learning: a guidebook to moderating intercultural collaboration online. Bern: Peter Lang.

[15] Gillies R \& Boyle M. 2007. Cooperative learning: a smart pedagogy for successful learning. Queensland: school of education The Universiy of Queensland.

[16] Cheung, D. (2011) Evaluating student attitude toward chemistry lessons to enhance teaching in the secondary school. Educacion Quimica, 22(2), 1-8.

[17] Aiken, L.R. (1985). Three coefficients for analyzing the reliability and validity of ratings. Educational and Psychological Measurement, 45, 131-142.

[18] Retnawati, H. (2016). Analisis kuantitatif instrumen penelitian: panduan peneliti, mahasiswa, dan psikometrian. Yogyakarta: Parama Publishing.

[19] Froyd J. 2015. Positive interdependence, individual accountability, promotive interaction: three pillars of cooperative learning. http://www.foundationscoalition.org.

[20] Snyder, J.J., Sloane, J.D., Dunk, R.D.P., \& Wiles, J.R. (2016). Peer Led Team Learning Helps Minority Students Succeed. Plos Biol, 14(3), 1-7.

[21] Pamela White, D.N.P., Amy Beth Rowland, M.S., Irene Pesis-Katz. (2012). Peer Led Team Learning Model in a Graduate-Level Nursing Course. Journal of Nursing Education 51(8), 471-475.

[22] Snyder, J.J., Carter, B.E., Wiles, J.R. (2015) Implementation of the peer led team learning instructional model as a stopgap measure improves student achievement for students 
opting out of laboratory. CBE-Life Sciences Education, 14, 1-6.

[23] Johnston, E.C., Robbins, B.A., \& Loui, M.C. (2015). What do students experience as peer leader of learning teams. Advances in Engineering Education, 1, 1-22.

[24] Koeslag-Kreuner, M., Van de Bossche, P., Hoven, M., Van der Klink, M., \& Gijselaers, W. (2018). When leadership powers team learning s meta analysis. Small Group Research 49(4), 475-513. 